\title{
Injection therapy for nonvariceal gastrointestinal bleeding
}

\author{
PAUL KORTAN, MD, FRCPC
}

\begin{abstract}
Gastrointestinal hemorrhage is a common and serious problemits average mortality of $10 \%$ has changed little over the past 40 years. In $80 \%$ of patients the bleeding stops spontaneously. In patients with continuous or recurrent bleeding $(20 \%)$, mortality and morbidity are high, and emergency surgery is often required, which has a higher mortality than the same operation performed electively. Successful therapeutic endoscopic intervention in this high risk group is necessary to improve outcome. For injection treatment of nonvariceal bleeding lesions, the author has been using the Soehendra method $(1: 10,000$ adrenaline and polidocanol) with success in $90 \%$ of actively bleeding patients. Three controlled trials of endoscopic sclerosis in bleeding peptic ulcer disease showed decreased blood transfusions, surgery and hospital stay, but did not find any significant difference in mortality. The ideal solution and the usefulness of additional therapy are questions which must be addressed via prospective controlled trials of a large number of patients. Can J Gastroenterol 1990;4(9):650-652
\end{abstract}

Key Words: Adrenaline, Gastrointestinal bleeding, Hemostasis, Injection therapy

\section{Traitement par injection des hémorragies gastrointestinales non variqueuses}

RESUME: L'hémorragie gastro-intestinale est un problème courant sérieux qui s'accompagne d'une mortalité moyenne de $10 \%$, chiffre qui a peu changé au cours des quarante dernières années. Chez $80 \%$ des patients, l'hémorragie cesse spontanément. Chez les patients qui saignent constamment ou dont les saignements récidivent $(20 \%)$, la mortalité et la morbidité sont élevées et une intervention d'urgence s'impose souvent, laquelle est assortie d'un taux de mortalité supérieure à celle des mêmes opérations à froid. Dans ce groupe à risque élevé, il est nécessaire de recourir aux interventions endoscopiques thérapeutiques afin d'améliorer les résultats. L'auteur a recours au traitement par injection des lésions non variqueuses qui saignent; il utilise la méthode de Soehendra (1: 10000 adrénaline et polidocanol) avec succès chez $90 \%$ des patients qui saignent activement. Trois essais contrôlés utilisant des injections sclérosantes effectuées sous endoscopie dans le traitement des ulcères gastroduodénaux hémorragiques rapportent une diminution des transfusions, des gestes

Division of Gastroenterology, University of Toronto, The Wellesley Hospital, Toronto, Ontario

Correspondence and reprints: Dr P Kortan, Assistant Professor, Division of

Gastroenterology, University of Toronto, The Wellesley Hospital, 160 Wellesley Street East,

Suite 419, Jones Building, Toronto, Ontario M4Y $1 \mathrm{J3}$
ASTROINTESTINAL HEMORRHAGE
is a common and serious problem with an average mortality of $10 \%$ (1). lt is often assumed that early correct diag. nosis will reduce mortality rates; how. ever, several controlled studies have shown no such advantage, and there has been little change in mortality over the past 40 years. Since the vast majority of upper gastrointestinal bleeding episodes are self-limited, it has been estimated that more than 5000 patients would have to be randomized before a trial could demonstrate that endoscopy decreases mortality. More importantly, the majority of endoscopic trials were carried out before the evolu. tion of therapeutic techniques that can potentially control gastrointestinal bleeding $(2,3)$.

In $80 \%$ of patients, the bleeding stops spontaneously and the hospital course is usually benign. However, in patients with continuous or recurrent bleeding (20\%), mortality and morbidity are high and emergency surgery is often needed (4). Emergency surgery for upper gastrointestinal bleeding is as. sociated with a higher mortality than for the same operation performed elec. tively. Successful therapeutic endoscopic intervention in this high risk group is necessary to improve the outcome. A number of endoscopic therapeutic modalities are now avail. able to treat upper gastrointestinal 
chirurgicaux et des hospitalisations, mais ne montrent aucune différence significative quant à la mortalité. Il faudrait examiner quelles seraient la solution idéale et l'utilité d'un traitement additionnel à l'aide d'essais prospectifs contrôlés portant sur un grand nombre de patients.

bleeding. These include yttriumaluminum-garnet (YAG) laser, monopolar and bipolar coagulation, heater probe and injection therapy. None of these modalities has been sufficiently well studied to permit definitive recommendations.

The ideal hemostatic technique should be simple, safe, portable, inexpensive and effective. These criteria are best fulfilled by injection therapy. Injection sclerotherapy has been used extensively in the control of bleeding esophageal varices and over the past few years has gained popularity for nonvariceal bleeding. The technique has been practised in Japan and West Germany since the mid 1970s (5). A number of different substances have been injected, most of which are vasoconstrictors or sclerosants. Table 1 lists the injectable agents that have been used for treatment of upper gastrointestinal bleeding.

\section{TECHNIQUE}

Once an active or potential bleeding site has been accurately located, injection therapy can be attempted. The injection is performed using a variceal injector. A large single or double channel endoscope is preferred to allow for adequate suctioning of blood. Sclerosant or vasoconstrictor is injected at three or four sites surrounding an exposed bleeding vessel or nonbleeding visible vessel. The volume of agent injected depends on the type and should be minimized to avoid extension of ulcer and transmural injury.

\section{MECHANISMS OF ACTION}

The hemostatic mechanism of injectable agents is based on vasoconstricting or sclerosing effect.

Adrenaline in animal experiments has been shown to cause a prolonged decrease in local gastric bloodflow (68). The decrease in flow is felt to be secondary to the vasoconstrictive effect of adrenaline rather than to a mechanical effect of the injected volume.

Injection of absolute ethanol has been shown to cause degeneration and necrosis of the blood vessel wall with consequent thrombosis $(9,10)$. This is accomplished by the fixative effect of ethanol. Part of the hemostasis may be supported by mechanical compression of vessels.

Hypertonic saline was shown to cause tissue edema, degeneration of vascular wall and consequent thrombosis in the vascular lumen (11).

Rutgeerts (12) examined the tissue effects of adrenaline 1:10,000, absolute alcohol and $1 \%$ polidocanol, and compared them with YAG laser and BICAP in dogs. Adrenaline caused focal damage without thrombosis of submucosal vessels and without serositis. Ethanol caused dehydration and fixation of the tissue with extensive submucosal and muscular necrosis and vessel thrombosis. Serositis was frequently observed. There was a linear relationship between the extent of damage and the volume of solution injected. Injection of $1 \%$ polidocanol caused lesions characterized by mucosal necrosis, partial necrosis of submucosa and submucosal edema. There was partial thrombosis of the vessels. The extent of damage from $1 \%$ polidocanol was related to the volume injected.

\section{CLINICAL EXPERIENCE}

Uncontrolled studies have been reported on the use of injection treatment with a number of different hemostatic agents, with successful treatment ranging from 84 to $100 \%$. Asaki (9) injected absolute alcohol and obtained hemostasis in $100 \%$ of patients with $10 \%$ rebleeding. Sugawa (13) also using alcohol obtained permanent hemostasis in $88 \%$ of patients. Soehendra (14) has been injecting adrenaline 1:10,000 combined with $1 \%$ polidocanol and obtained hemostasis in $84 \%$ of pulsatile
TABLE 1

Injectable agents used for treatment of upper gastrointestinal bleeding

Adrenaline 1:10,000

Adrenaline and hypertonic saline solution

Adrenaline 1:10,000 followed by

polidocanol

Absolute ethanol

Thrombin

Ethanolamine

bleeders. Leung (15) used adrenaline alone with permanent hemostasis in $92 \%$ of patients.

Rutgeerts and colleagues (16) randomized 140 patients with ulcers containing an actively bleeding or nonbleeding visible vessel to sham treatment or to one of three endoscopic methods of hemostasis: adrenaline $1: 10,000$ alone, adrenaline $1: 10,000$ plus $1 \%$ polidocanol, and adrenaline followed by YAG laser treatment. In patients with a nonbleeding visible vessel, the sham treatment was significantly less effective than adrenaline plus polidocanol or adrenaline plus laser in achieving hemostasis. All three treatments reduced total transfusion requirement significantly compared with sham treatment. Adrenaline plus polidocanol was significantly more effective than adrenaline alone in achieving permanent hemostasis. Adrenaline plus laser was also more effective than adrenaline alone, but this difference was not statistically significant. The authors concluded that injection therapy with adrenaline plus polidocanol should be the treatment of choice based on cost, ease of use and safety.

A recent report from Spain documents the efficacy of this technique in a controlled trial (17). One hundred and thirteen patients with hemorrhage were randomized to endoscopic injection therapy and $\mathrm{H}_{2}$ blockers, or to $\mathrm{H}_{2}$ blockers alone. Each group had an equal number of patients with bleeding and nonbleeding visible vessels. All lesions were injected with 3 to $10 \mathrm{~mL}$ of adrenaline $1: 10,000$ and 6 to $12 \mathrm{~mL}$ of $1 \%$ polidocanol. Major recurrent bleeding occurred in $5 \%$ of injected patients and in $23 \%$ of patients randomized to 
treatment with $\mathrm{H}_{2}$ blockers alone $(\mathrm{P}<0.001)$. The need for emergency surgery was reduced from 34 to $5 \%$ $(\mathrm{P}<0.001)$ and there was a significantly reduced requirement for blood transfusions and a reduction in the length of hospital stay.

A second randomized study by Chung et al (18) compared injection of adrenaline into bleeding ulcers with no endoscopic treatment. There was a significant difference in the two groups with respect to requirement for emergency surgery, requirement of blood transfusion and median hospital stay.

The third prospective randomized trial was carried out by Balanzo et al (19). They studied 72 patients with

\section{REFERENCES}

1. Silverstein FE, Gilbert DA, Tedesco FJ, Buenger NK, Persing J. The National ASGE survey on upper gastrointestinal bleeding. I. Study design and baseline data. Gastrointest Endosc 1981;27:73-9.

2. Silverstein FE, Gilbert DA, Tedesco FD, Buenger NK, Persing J. The National ASGE survey on upper gastrointestinal bleeding. II. Clinical prognostic faceors. Gastrointest Endosc 1981;27:80-93.

3. Morgan AG, Clamp SE. OMGE international upper gastrointestinal bleeding survey 1978-1982. Scand ] Gastroenterol 1984;19(Suppl 95):4158.

4. Fleischer D. Etiology and prevalence of severe persistent upper gastrointestinal bleeding. Gastroenterology 1983;84:538-43.

5. Soehendra N, Werner BL. New technique for endoscopic treatment of bleeding gastric ulcer. Endoscopy 1976;8:85-7.

6. Leung FW, Sung JY, Chung SCS, Leung JWC. Endoscopic assessment of mucosal hemodynamic changes in a canine model of gastric ulcer. Gastrointest Endosc 1989;35:186.

7. Chung SCS, Leung FW, Leung JWC. Is vasoconstriction the mechanism of hemostasis in bleeding ulcers injected bleeding ulcers. Half were randomized to injection treatment with adrenaline plus polidocanol and half were managed medically. The study again confirmed the benefit of injection therapy comparing the requirement for emergency surgery and blood transfusions. None of these studies was able to show a significant difference in mortality.

\section{COMPLICATIONS}

The use of polidocanol has been associated with the appearance of large ulcers when more than $20 \mathrm{~mL}$ have been injected. The perforation rate is $1 \%$ (20). Injection of absolute alcohol has been associated with a less than $1 \%$ perforation rate (13).

with epinephrine? A study using reflectance spectrophotometry. Gastrointest Endosc 1988;34:174.

8. Chung SCS, Suen MWM, Galvina M, Lee TW, Leung JWC. The effect of submucosal epinephrine on blood loss from standard bleeding ulcers. Gastrointest Endosc 1988;34:189-90.

9. Asaki S, Nishimura T, Satoh A, Goto Y. Endoscopic control of gastrointestinal hemorrhage by local injection of absolute ethanol: $\mathrm{A}$ basic assessment of the procedure. Tohuku J Exp Med 1983;140:339-52.

10. Sugawa C, Fujita Y, Lucas CE, Raval M, Masuyama H. Hemostatic effect of local intramural injection of dehydrated ethanol in the canine gastrointestinal tract. Gastrointest Endose 1989;35:28-32.

11. Hirao M, Kobayashi T, Masuda K, et al. Endoscopic local injection of hypertonic saline-epinephrine solution to arrest hemorrhage from the upper gastrointestinal tract. Gastrointest Endosc 1985;31:313-7.

12. Rutgeerts P, Geboes K, Vantrappen G. Experimental studies of injection therapy for severe nonvariceal bleeding in dogs. Gastroenterology 1989;97:61021.

13. Sugawa C, Fujita Y, Ikeda T, Walt AJ. Endoscopic hemostasis of ninety eight percent dehydrated ethanol. Surg

\section{CONCLUSIONS}

Injection sclerotherapy nonvariceal gastrointestinal bleedir is the least expensive and most wide available form of endoscopic therap The technique of injection treatmet is easy to learn, and most endoscopis who practice sclerotherapy esophageal varices are able to perforn this procedure. The controlled studie up to the present time have shown reduction in the requirement fo blood transfusions, decreased need fo surgery, shorter hospital stay an therefore a lower overall cost. Hope fully larger controlled studies wil show a significant impact on mor tality.

Gynecol Obstet 1986;162:161-3.

14. Soehendra N, Grimm H, Stenzel M. Injection of non-variceal bleeding lesions of the gastrointestinal tract. Endoscopy 1985;17:129-32.

15. Leung JWC, Chung SCS. Endoscopic injection of adrenalin in bleeding peptic ulcer. Gastrointest Endosc 1987;33:73-5.

16. Rutgeerts P, Vantrappen G, Broeckaett L, Coremans G, Janssens J, Hiele M. Comparison of endoscopic polidocanol injection and YAG laser therapy for bleeding peptic ulcers. Lancet $1989 ; i: 1164-7$.

17. Panes J, Viver J, Forne M, GarciaOlivares E, Marco C, Garau J. Controlled trial of endoscopic sclerosis in bleeding peptic ulcers. Lancet 1987;ii:1292-4.

18. Chung SCS, Leung JWC, Steele RJC, Crofts T], Li AKC. Endoscopic injection of adrenaline for actively bleeding ulcers: A randomised trial. Br Med ] 1988;296:1631-3.

19. Balanzo J, Sainz S, Such J, et al. Endoscopic hemostasis by local injection of epinephrine and polidocanol in bleed. ing ulcer. A prospective randomized trial. Endoscopy 1988;20:289-91.

20. Wordehoff D, Gros H. Endoscopic hemostasis by injection therapy in high risk patients. Endoscopy 1982;14:196-9. 


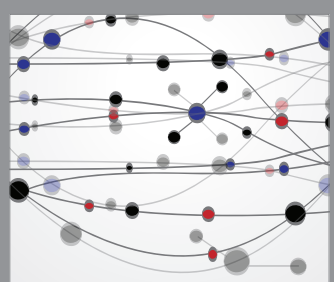

The Scientific World Journal
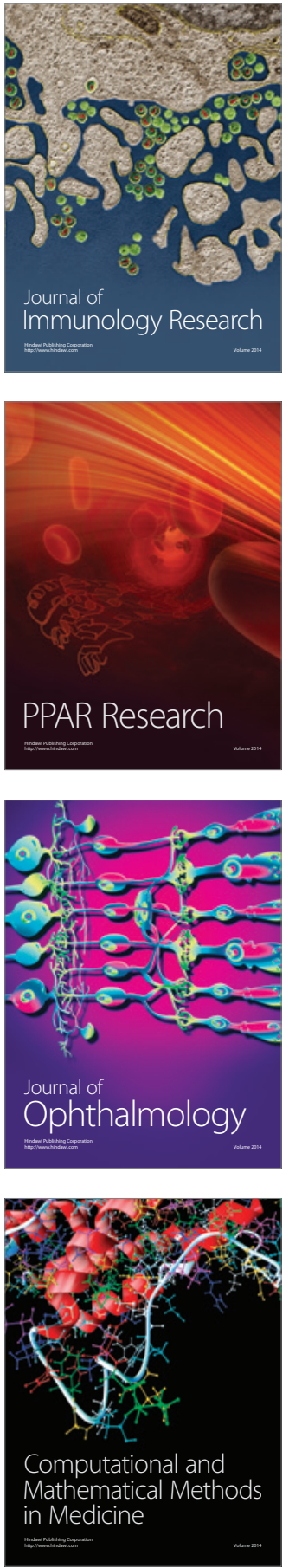

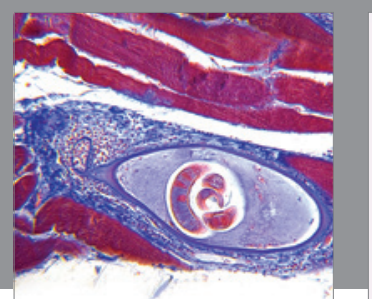

Gastroenterology Research and Practice

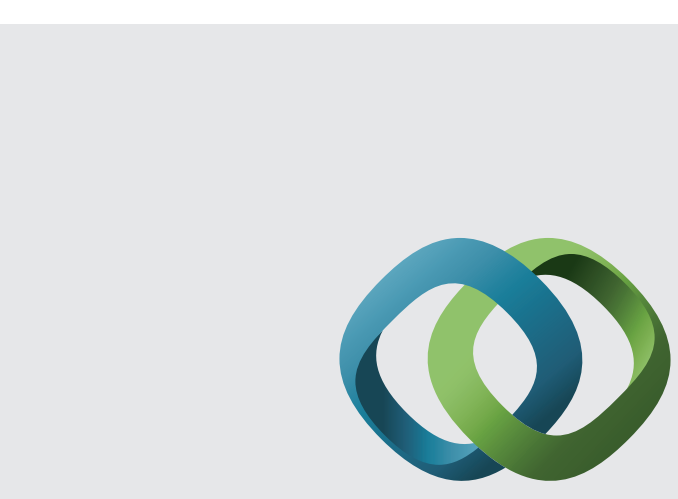

\section{Hindawi}

Submit your manuscripts at

http://www.hindawi.com
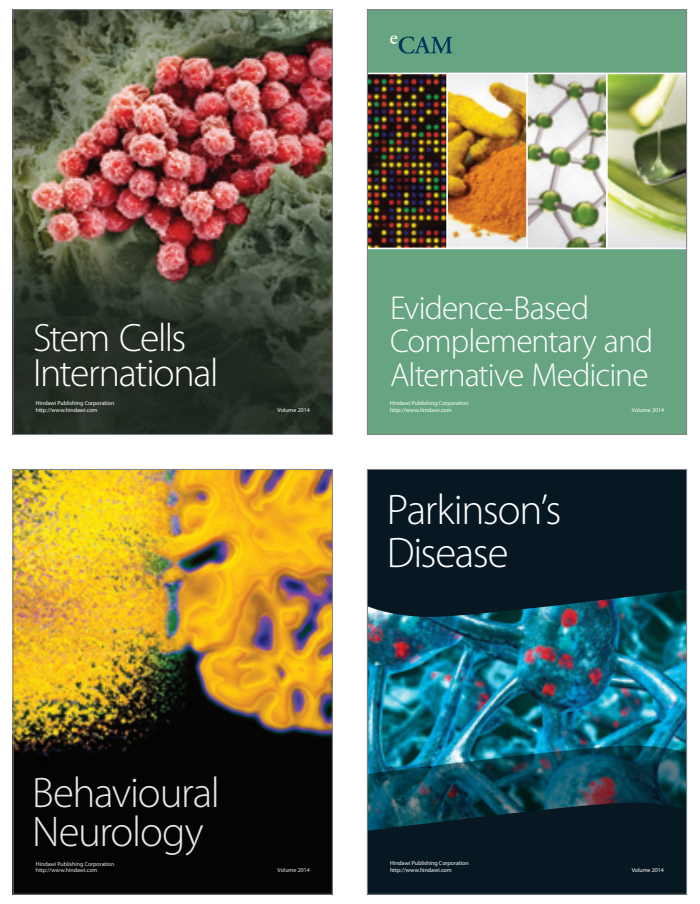
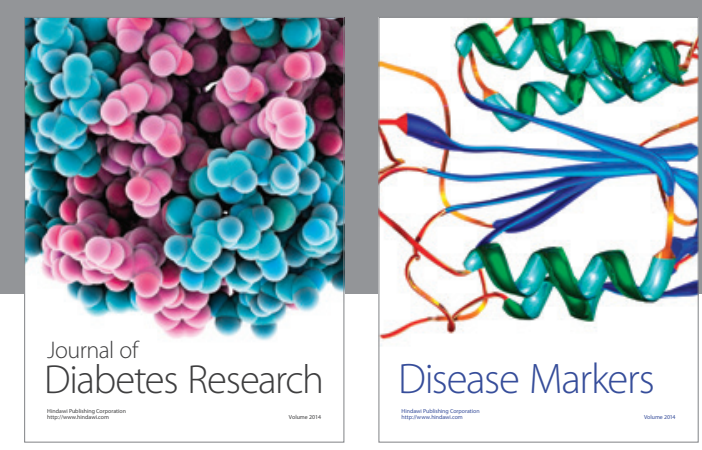

Disease Markers
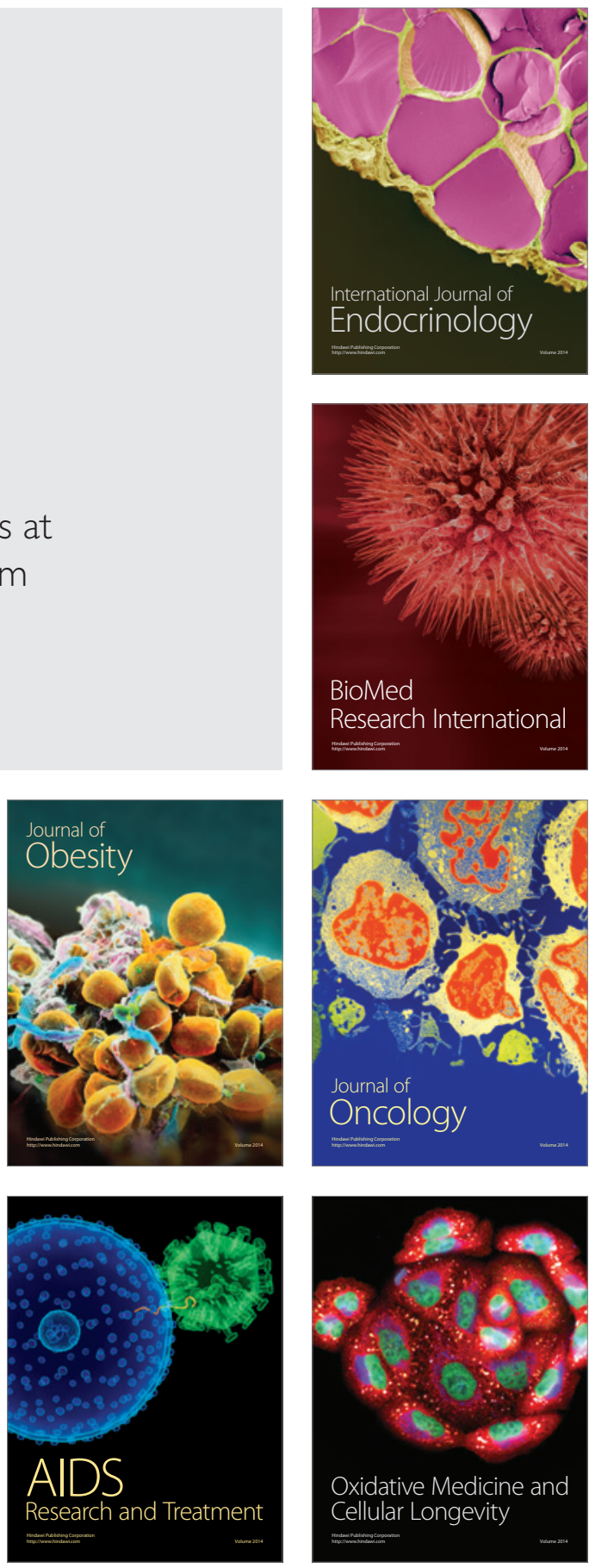